\title{
Vagotomy and gallbladder function
}

\author{
STIG FAGERBERG, SVEN GREVSTEN, HENRY JOHANSSON, AND \\ URBAN KRAUSE \\ From the Departments of Radiology and Surgery, University of Uppsala, Sweden
}

SUMMARY The effect of vagotomy on gallbladder function was investigated in a clinical and experimental study. In the clinical study both the size of the gallbladder and its capacity to respond to cholecystokinin were evaluated radiologically before and after vagotomy. In studies in the rabbit, both the immediate effect of vagotomy on the gallbladder and the effect of varying doses of cholecystokinin on gallbladder pressure were studied before and after vagotomy. In studies in the cat the long-term effect of vagotomy was studied with respect to the histology of the gallbladder and the composition of bile.

The clinical investigation showed that vagotomy was followed by a significant increase in the volume of the gallbladder and that the effect of the cholecystokinin on the gallbladder remained unchanged after vagotomy. In experiments in the rabbit it was found that cholecystokinin in a dose of $1 \mathrm{unit} / \mathrm{kg}$ body weight exerted a somewhat lesser effect on gallbladder pressure after vagotomy than before, while after vagotomy a dose, approximately four times greater, resulted in a stronger gallbladder response. Further, the experiments showed that the chemical composition of the bile seemed to be altered after vagotomy, while the gallbladder remained histologically essentially unchanged.

Clinical observations indicate that there is an increased frequency of gallstone disease after gastric surgery (Krause, 1963; Lundman, Orinius, and Thorsén (1964). Many theories have been presented to explain this. It has been considered that the inadvertent severance of branches of the vagus nerve to the liver and gallbladder, which often occurs in gastrectomy, might cause atonia of the gallbladder predisposing to the formation of stones (Roux, Baumel, and Vidal, 1959; Bernt, 1960; Griffiths and Holmes, 1964). Johnson and Boyden (1943). Also Pallin and Skoglund (1961) have shown that the right, and also to a lesser extent the left, vagus nerve has a contractile influence on the gallbladder. Other authors have postulated that the rapid passage of food substances through the duodenum, in Received for publication 1 November 1969. particular, decreases the secretion of cholecystokinin and thereby causes poor evacuation of the gallbladder (Roux et al, 1959; Griffiths and Holmes, 1964). It has also been suggested that adhesions after gastric surgery may cause distortion of the gallbladder and biliary tree. An abnormal bacterial growth, especially in the afferent loop after a Billroth II resection but also in the gastric remnant after both Billroth $I$ and Billroth II operations, due to postoperative achylia, has been discussed as a possible cause (Lenzenweger, 1959).

As the most prevalent hypothesis has been to ascribe the increased frequency of gallstones in man to vagotomy-a view further confirmed by some studies in animals-we decided to study the effect of vagotomy on the gallbladder and the response of the gallbladder to cholecystokinin 
administered before and after vagotomy. The investigation was carried out on the following lines. (1) A clinical study, in which both the size of the gallbladder and its contraction in response to cholecystokinin were assessed by radiology before and after vagotomy. (2) Studies in the rabbit, where the immediate effect of vagotomy was studied under varying experimental conditions and where the effect of cholecystokinin was determined before and after vagotomy. (3) Studies in the cat, where the long-term effect of vagotomy was investigated with respect to the histology of the gallbladder and the composition of the bile.

\section{Material and Methods}

\section{CLINICAL STUDIES}

Gallbladder function was investigated by means of oral cholecystography in 13 patients $(11$ men and 2 women) undergoing total vagotomy and a drainage procedure for gastroduodenal ulcer disease. Their ages ranged between 28 and 76 years, an average of 55 years. A preoperative examination was performed within 15 days before the operation and a postoperative examination after an average interval of five months. The patients were examined in a supine position with vertical and horizontal beams (antero-posterior and lateral projections respectively). The volume of the contrast-filled gallbladder was measured before and two, five, 10, and 20 minutes after intravenous administration of 75 units of cholecystokinin (Cecekin) dissolved in $10 \mathrm{ml} \mathrm{NaCl}$. The volume of the gallbladder was computed by the method of Edholm (1960) according to Simpson's formula for numeric integration:

$V=\frac{D}{18}\left(4 a_{1}+2 a_{2}+4 a_{3}+2 a_{4}+4 a_{5}\right) \ldots$.

where $a_{1}, a_{2}, a_{3}, a_{4}$, and $a_{5}$ are cross-sectional areas $\frac{D}{6}$ equidistantly spaced and $D$ is the great-

est length of the lateral and anterior-posterior projections. The cross-sectional areas are assumed to be approximately elliptical and calculated as the product of the semiaxes from the lateral and antero-posterior projections and $\pi$. A slight modification was made to Edholm's method; thus on account of other present errors the reduction factors for $D$ and the semiaxes of the two projections were stated to be the same and approximated to 0.85 throughout the study (with FFD $100 \mathrm{~cm}$ in both projections). Formula (1) was thus simplified to

$V=\frac{D \times F^{3}}{9}\left(2 a_{1}+a_{2}+2 a_{3}+a_{4}+2 a_{5}\right) \ldots$

where the reduction factor $F=0 \cdot 85$.
EXPERIMENTAL STUDIES

Gallbladder pressure and the effect of cholecystokinin before and after vagotomy

The experiments were performed on 16 rabbits. The animals were anaesthetized with Nembutal (Abbott) given intravenously in a dose of 35 $\mathrm{mg} / \mathrm{kg}$ body weight. The abdomen was opened through an oblique incision below the right costal arch. The gallbladder pressure was recorded by means of a technique described by Ivy and Janecek (1959), in which a polyethylene catheter was inserted into the gallbladder. In all the experiments the cystic duct was dissected free from the vessels and ligated. The stabilized initial pressure was taken as the baseline value. The vagotomy was performed on the right side of the neck. The dissection to free the vagus nerve was performed after the initial gallbladder pressure had been measured to avoid vagus effects being recorded by touching the nerve.

To record the action of cholecystokinin (Cecekin) the dose given in series 1 was 1 unit $/ \mathrm{kg}$ body weight (total dose 2-4 units) and in series 2 the effect of the hormone was studied after injecting a total dose of 10 units, ie, approximately four times as much as in series 1 . Cholecystokinin was administered intravenously. The effect of the hormone after vagotomy was studied 20 minutes after the resection of the nerve when the pressure was stabilized. The action of cholecystokinin was recorded as a peak pressure.

Analysis of chemical substances and physical properties of gallbladder bile after vagotomy

The experiments were made on eight cats. The vagotomy was performed transperitoneally through a midline incision. At operation the animals were anaesthetized with Nembutal (Abbott) given intraperitoneally in a dose of $\mathbf{4 0}$ $\mathrm{mg} / \mathrm{kg}$ body weight. The identification of the vagus nerves and subsequent resection of the nerve branches were performed under careful inspection. Pyloroplasty was carried out as a drainage procedure.

The gallbladder bile was analysed three to seven months after vagotomy and the vagotomized cats were compared with untreated controls. The analyses were of the following chemical substances and physical properties: calcium, bilirubin, cholesterol, and hydrogen ion concentrations. The calcium analysis was performed by flame photometry (Eppendorf). Bilirubin levels were determined according to the method of Michaelsson (1963) and cholesterol levels according to the method of Swedin (1965). The hydrogen ion concentration was determined with a $p \mathrm{H}$ meter $(p \mathrm{H}$ meter 27 , Radiometer, Copenhagen) in a microglass electrode measuring chamber, according to Astrup.

HISTOLOGICAL EXAMINATION The gallbladders were examined morphologically 


\begin{tabular}{|c|c|c|c|c|c|c|c|c|c|}
\hline \multicolumn{4}{|c|}{ Initial Volume } & \multicolumn{6}{|c|}{ Emptying Volume } \\
\hline \multirow[t]{2}{*}{ Sex } & \multirow[t]{2}{*}{$\begin{array}{l}\text { Before } \\
\text { Vagotomy }(\mathrm{ml})\end{array}$} & \multirow[t]{2}{*}{$\begin{array}{l}\text { After } \\
\text { Vagotomy }(\mathrm{ml})\end{array}$} & \multirow[t]{2}{*}{$\begin{array}{l}\text { Volume } \\
\text { Increase }(\mathrm{ml})\end{array}$} & \multicolumn{2}{|c|}{$\begin{array}{l}\text { Before } \\
\text { Vagotomy }\end{array}$} & \multicolumn{2}{|c|}{$\begin{array}{l}\text { After } \\
\text { Vagotomy }\end{array}$} & \multirow[t]{2}{*}{ Difference (\%) } & \multirow[t]{2}{*}{$\begin{array}{l}\text { Postoperative } \\
\text { Time (mth) }\end{array}$} \\
\hline & & & & $m l$ & $\%$ & $m l$ & $\%$ & & \\
\hline $\begin{array}{l}\mathbf{F} \\
\mathbf{M} \\
\mathbf{M} \\
\mathbf{M} \\
\mathbf{M} \\
\mathbf{M} \\
\mathbf{M} \\
\mathbf{F} \\
\mathbf{M} \\
\mathbf{M} \\
\mathbf{M} \\
\mathbf{M} \\
\mathbf{M}\end{array}$ & $\begin{array}{l}72 \cdot 1 \\
27 \cdot 7 \\
24 \cdot 6 \\
43 \cdot 6 \\
34 \cdot 9 \\
43 \cdot 1 \\
34 \cdot 4 \\
14 \cdot 4 \\
27 \cdot 2 \\
23 \cdot 0 \\
39 \cdot 1 \\
46 \cdot 3 \\
11 \cdot 3\end{array}$ & $\begin{array}{r}110 \cdot 1 \\
52 \cdot 1 \\
44 \cdot 0 \\
52 \cdot 0 \\
60 \cdot 0 \\
69 \cdot 6 \\
82 \cdot 4 \\
16 \cdot 3 \\
37 \cdot 7 \\
18 \cdot 9 \\
46 \cdot 4 \\
38 \cdot 3 \\
12 \cdot 2\end{array}$ & $\begin{array}{r}38.0(54.1 \%) \\
30.4(140.0 \%) \\
19.4(78.9 \%) \\
8.4(19.3 \%) \\
25.1 \quad(71.9 \%) \\
26.5(61.5 \%) \\
48.0(139.5 \%) \\
1.9(13.2 \%) \\
10.5 \quad(38.9 \%) \\
-4.1 \\
7.3 \quad(18.7 \%) \\
-8.0 \\
0.9 \quad(7.0 \%)\end{array}$ & $\begin{array}{r}35 \cdot 7 \\
27 \cdot 7 \\
8 \cdot 7 \\
24 \cdot 5 \\
12 \cdot 4 \\
29 \cdot 4 \\
16 \cdot 8 \\
7 \cdot 2 \\
5 \cdot 5 \\
27 \cdot 4 \\
24 \cdot 2 \\
9 \cdot 4\end{array}$ & $\begin{array}{r}49 \cdot 5 \\
100 \cdot 0 \\
31 \cdot 3 \\
56 \cdot 2 \\
35 \cdot 5 \\
68 \cdot 3 \\
48 \cdot 8 \\
50 \cdot 0 \\
0 \cdot 0 \\
23 \cdot 9 \\
70 \cdot 1 \\
52 \cdot 3 \\
83 \cdot 2\end{array}$ & $\begin{array}{r}98 \cdot 2 \\
52 \cdot 1 \\
17 \cdot 3 \\
52 \cdot 0 \\
15 \cdot 1 \\
47 \cdot 8 \\
57 \cdot 8 \\
11 \cdot 2 \\
6 \cdot 9 \\
7 \cdot 7 \\
21 \cdot 9 \\
14 \cdot 2 \\
10 \cdot 9\end{array}$ & $\begin{array}{r}89 \cdot 2 \\
100 \cdot 0 \\
39 \cdot 3 \\
100 \cdot 0 \\
25 \cdot 2 \\
68 \cdot 7 \\
70 \cdot 0 \\
68 \cdot 2 \\
18 \cdot 3 \\
40 \cdot 7 \\
47 \cdot 2 \\
37 \cdot 2 \\
89 \cdot 3\end{array}$ & $\begin{array}{r}+39.7 \\
0.0 \\
+8.3 \\
+43.8 \\
-10.3 \\
+0.4 \\
+21 \cdot 2 \\
+18.7 \\
+18.3 \\
+16.8 \\
-22.9 \\
-15.1 \\
+6.1\end{array}$ & $\begin{array}{l}2 \\
2 \\
4 \\
8 \\
2 \\
2 \\
8 \\
8 \\
8 \\
2 \\
2 \\
8 \\
8\end{array}$ \\
\hline Mean & $33 \cdot 5$ & $49 \cdot 2$ & $\begin{array}{l}15.7(\mathrm{SE}=4.5 \\
\text { significant for } \\
0.001<\mathrm{P}<0.01)\end{array}$ & $\begin{array}{l}17 \cdot 6 \\
)\end{array}$ & $\begin{array}{l}51 \cdot 5 \\
(\mathrm{SE}= \\
7 \cdot 2)\end{array}$ & $31 \cdot 7$ & $\begin{array}{l}61 \cdot 1 \\
(\mathrm{SE}= \\
7 \cdot 9)\end{array}$ & $\begin{array}{l}9 \cdot 6(\mathrm{SE}=5 \cdot 5, \mathrm{n} \\
\text { significant })\end{array}$ & \\
\hline
\end{tabular}

Table I Initial volume and emptying function of the gallbladder before and after vagotomy

in sections $5 \mu$ thick stained with haematoxylin and eosin and Sudan III.

\section{Results}

\section{CLINICAL OBSERVATIONS}

The volume of the gallbladder before operation varied between 11 and $72 \mathrm{ml}$ (average of $33 \mathrm{ml}$ ). The volume after operation varied between 12 and $110 \mathrm{ml}$ (average of $49 \mathrm{ml}$ ). The individual differences before and after operation were calculated and a significant average increase was observed after vagotomy. Following the injection of cholecystokinin the maximal emptying was noted after 20 minutes.

After the administration of cholecystokinin the volume of the gallbladder decreased by an average of $18 \mathrm{ml}$ before and $32 \mathrm{ml}$ after vagotomy. The emptying function of the gallbladder was estimated by expressing the volume of the gallbladder as a percentage of the initial volume (Table I). The preoperative percentage value was $51.5 \%$ and the postoperative $61 \cdot 1 \%$. The individual mean percentage differences did not differ significantly before or after operation.

\section{EXPERIMENTAL OBSERVATIONS}

\section{Pressure in the gallbladder}

The initial pressure in the gallbladder varied between 2.5 and $4.5 \mathrm{~cm}$ bile and vagotomy was followed by a decrease $(0.5-1.5 \mathrm{~cm}$ bile) in pressure in 13 out of 16 cases. This pressure decrease was seen within two to five minutes. In the three other cases the pressure was unchanged.

The dose of 1 unit cholecystokinin/ $\mathrm{kg}$ body weight (series 1) induced a rise of pressure in the gallbladder varying from 1.5 to $3.1 \mathrm{~cm}$ bile. The effect of cholecystokinin was observed immediately after the injection, with a maximal pressure increase within one to three minutes. This was followed by a decrease, the pressure finally settling at the initial value. After vagotomy the response to cholecystokinin was smaller in all cases in series 1. The maximal increase was reached, as before vagotomy, within one to three minutes after administration of the hormone (see Figure).

In series 2 where a total dose of 10 units of cholecystokinin was used, the hormone caused a pressure rise of 3.0 to $5.5 \mathrm{~cm}$ bile. The increase started immediately and a maximal value was obtained within three minutes. This was followed by a successive decrease with a final return to the initial value.

After vagotomy cholecystokinin gave a stronger response than before in seven of eight of the cases. The maximal pressure increase was usually not reached until after 10 minutes (Fig.).

In control experiments it was found that such manipulations as stretching and touching of the vagus nerve contributed to variations in the pressure of the gallbladder. In another control experiment, where vagotomy alone was performed, it was verified that the resection of the right vagus was followed by a decrease in the pressure $(0.5-1.5 \mathrm{~cm}$ bile) in the gallbladder in five of the six cases. The pressure decrease was seen within two to five minutes.

Chemical substances and physical properties of gallbladder bile

The chemical and physical properties of the gallbladder bile following vagotomy are shown in Table II, where the vagotomized animals are compared with the untreated controls. Increases in the contents of calcium, bilirubin, and 


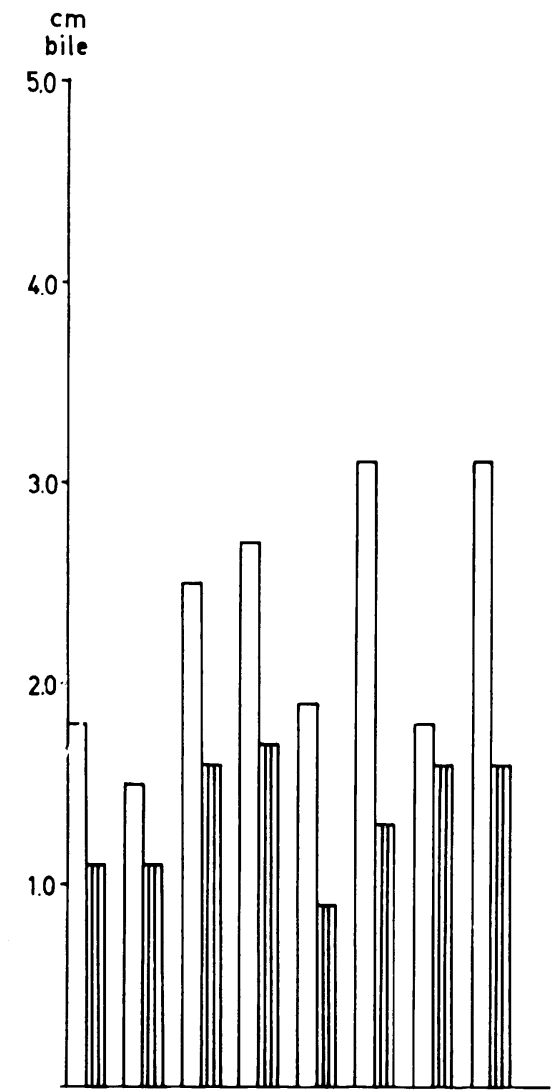

(a)

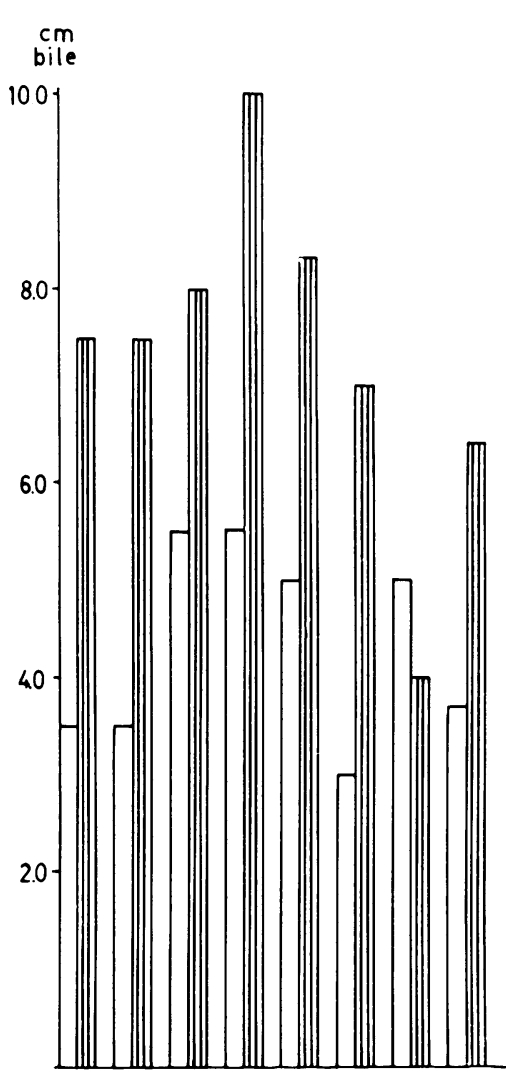

(b)

Fig. The effect of cholecystokinin on gallbladder pressure before and after (shaded area) vagotomy. (a) the pressure conditions after administration of 1 unit cholecystokinin/kg body weight, and (b) after administration of a total dose of 10 units.

cholesterol were noted after vagotomy. The $p \mathrm{H}$ value of the gallbladder bile was lower in the vagotomized group.

\begin{tabular}{lll}
\hline & \multicolumn{2}{l}{ Range } \\
\cline { 2 - 3 } & Controls & Vagotomized Animals \\
\hline Calcium (m-equiv/l) & $6 \cdot 3-11 \cdot 0$ & $24 \cdot 0-33 \cdot 0$ \\
Bilirubin (mg\%) & $21 \cdot 0-23 \cdot 0$ & $36 \cdot 0-163 \cdot 0$ \\
Cholesterol (mg\%) & $170-200$ & $480-600$ \\
Hydrogen ion concentration & $7 \cdot 16-7 \cdot 90$ & $5 \cdot 75-7 \cdot 32$ \\
\hline
\end{tabular}

Table II Chemical substances and hydrogen concentration in gallbladder bile

\section{Microscopy}

On microscopic examination it was found that in the vagotomized cats the gallbladder showed slightly oedematous and irregular villi which in some places contained in their proximal areas slightly dilated capillaries. No inflammatory changes were observed, and neither was there any

evidence of cholesterosis. Thus altogether the gallbladder exhibited only very insignificant changes.

\section{Discussion}

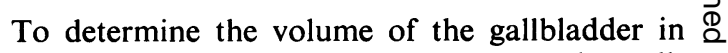
the clinical studies, only cases where the gall- is bladder was easily visualized were included. It is important to point this out, since a gallbladder which is difficult to visualize after oral administration of the contrast medium in gastrectomized patients need not necessarily mean the presence of biliary disease; the rapid propagation through the gastrointestinal tract after gastric surgery can result in poor absorption of the contrast medium (Owren, 1953; Goldeck and Gadermann, 1954; Krause, 1966). This possibility has not been taken into consideration in a number of reported clinical investigations.

The preoperative volume of the gallbladder was practically identical with that found by Edholm (1960) in his study. As was observed by Johnson and Boyden (1952), we also found a dilatation of the gallbladder after vagotomy, a result which is contradicted by Williams and Irvine (1966).

The pressure variations obtained in the experimental studies also demonstrated that the tonus of the gallbladder was decreased after vagotomy and that the effect of moderate doses of cholecystokinin on gallbladder pressure was slightly smaller after vagotomy. This indicates that the nerves have a tonic effect on the gallbladder wall. On the other hand, our clinical results showed that vagal denervation does not alter the effect of cholecystokinin intravenously administered on the emptying mechanism of the gallbladder. When using an 'overdose' of cholecystokinin the response to the hormone was in fact greater after vagotomy than before. These results may favour the theory that vagal denervation induces hypotonicity of the gallbladder. A possible explanation is that the reduced acid secretion or $\frac{7}{0}$ the duodenal exclusion in some forms of gastric surgery impairs cholecystokinin production (see $N$ Krause, 1963; Fletcher and Clark, 1968). It is N interesting to note that Pissidis (1968) has shown $\mathrm{N}$ that the regulation of bile production is probably influenced by the vagus branches from the gastric antrum. The humoral mechanism may be further $\stackrel{\circ}{\leftarrow}$ disturbed by the rapid passage of food through $\stackrel{\mathscr{Q}}{+}$ the upper part of the gastrointestinal tract 7 (Krause, 1963). The possible effect of assuming this hypothesis will be taken up in our further $\mathbb{D}$ studies in which gallbladder emptying will be $\stackrel{\oplus}{\mathbb{D}}$ induced by giving a fatty meal instead of cholecystokinin.

Manipulation of the vagus nerves by free dissection and the procedure of placing a ligature around the nerve mostly caused an increase in $\overline{0}$. gallbladder pressure. This is of interest, as most 
physiological experiments on the action of the vagus involve these procedures and thus possibly give a 'false' basic tonus. This effect of the manipulations on the gallbladder pressure may be caused by vagal stimulation liberating cholecystokinin from the duodenal mucosa (Uvnäs, 1942).

Denervation of the gallbladder in gastric surgery may lead to an alteration in the composition of the bile. Our experiments showed increased values for the levels of calcium, bilirubin, and cholesterol in gallbladder bile among vagotomized animals compared with intact controls. The hydrogen ion concentration showed a slight decrease after vagotomy. These biochemical alterations may indicate a stasis of the gallbladder contents. Alternatively, the division of the right vagus may modify the ciliary constituents by a direct action on the hepatic cells. Alteration in the biliary $p \mathrm{H}$ following gastric surgery is noted by Delgado-Pereira and Zerbino (1965) as a factor which may limit the cholesterolytic power of the bile, and Roux et al (1959) have drawn attention to changes in cholesterol and calcium phosphorus as being potentially lithogenic. It is also of interest that Hulten (1968) has suggested that electrolyte changes could lead to a shift in $p \mathrm{H}$ towards acidity; this together with water loss makes the mucus thicker. However, it is not known whether the mucous membrane activity is influenced by nervous impulses or hormonal impulses or both.

This work was supported by the Swedish Medical Research Council and the Magnus Bergwalls Foundation.

\section{References}

Bernt, O. (1960). Gallensteinbildung nach Magenresektion. Dtsch. Gesundth.-Wes., 15, 402-405.

Delgado-Pereira, B., and Zerbino, V. (1965). Pancreatitis postoperatoria en la cirurgia biliar. A propósito de observaciones. Rev. Cirug. Urug., 35, 154-161.

Edholm, P. (1960). Gallbladder evacuation in the normal male induced by cholecystokinin. Acta radiol. (Stockh.), 53, 257-265.

Fletcher, D. M., and Clark, C. G. (1968). Gallstones and gastric surgery. Brit. J. Surg., 55, 895.

Goldeck, H., and Gadermann, E. (1954). Zum Eisenstoffwechsel nach Magenresektion. Ärztl. Wschr., 9, 39-40.

Griffiths, J. M. T., and Holmes, G. (1964). Cholecystitis following gasiric surgery. Lancet, $2,780-782$.

Hulten, O. (1968). Formation of gallstones II. Acta chir. scand., 134, 557-561.

Ivy, A. C., and Janecek, H. M. (1959). Assay of Jorpes-Mutt secretin and cholecystokinin. Acta physiol. scand., 45, 220-230.

Johnson, F. E., and Boyden, E. A. (1943). The effect of sectioning various autonomic nerves upon the rate of emptying of the biliary tract in the cat. Surg. Gynec. Obstet., 76, 395-410.

Johnson, F. E., and Boyden, E. A. (1952). The effect of double vagotomy on the motor activity of the human gallbladder. Surgery, 32, 591-601.

Krause, U. (1963). Long term results of medical and surgical treatment of peptic ulcer. Acta chir. scand., Suppl. 310.

Krause, U. (1966). Treatment of post-gastrectomy iron-deficiency anaemia with reference to the absorption of iron administered in fluid and tablet form. Acta chir. scand., 132, 186-194.

Lenzenweger, F. (1959). Uber Gallensteinkrankheit als Folge nach Magenoperationen. Wien. klin. Wschr., 71, 13.

Lundman, P., Orinius, E., and Thorsén, G. (1964). Incidence of gallstone disease following partial gastric resection. Acta chir. scand., 127, 130-133.

Michaelsson, M. (1963). Bilirubin determination in serum and urine. Scand. J. clin. Lab. Invest., 13, Suppl. 56.

Owren, P. A. (1953). The pathogenesis and treatment of iron deficiency anemia after partial gastrectomy. Acta chir. scand., 104, 206-214.

Pallin, B., and Skoglund, S. (1961). On the nervous regulation of the biliary system in the cat. Acta physiol. scand., 51, 187-192.

Pissidis, A. (1968). Personal communication.

Roux, G., Baumel, H., and Vidal, J. (1959). Biliary lithiasis in patients gastrectomized for ulcer. Marseille chir., 11, 535-541.

Swedin, B. (1965). Internal paper from Central Laboratory, University Hospital, Uppsala.

Uvnäs, B. (1942). The part played by the pyloric region in the cephalic phase of gastric secretion. Acta physiol. scand. 4, Suppl. 13.

Williams, E. J., and Irvine, W. T. (1966). Functional and metabolic effects of total and selective vagotomy. Lancet, 1, 1053-1057. 